\title{
The Hijrian and Gregorian Electronic Obstetrical Calendar
}

\author{
Faisal M. Tallab ${ }^{1^{*}}$, FRCSC and Anas M. Al Marzouki ${ }^{2}$, FRCSC \\ ${ }^{1,2}$ Department of Obstetrics \& Gynecology \\ ${ }^{1}$ King Abdulaziz Hospital \& Oncology Center and \\ ${ }^{2}$ Faculty of Medicine, King Abdulaziz University \\ Jeddah, Saudi Arabia \\ tallabfm@yahoo.com
}

\begin{abstract}
Naegele's rule and obstetrical wheels have been used for many decades as tools to calculate the expected date of delivery. Reviewing the literature, it was found that pregnancy wheels provided by drug companies have margin error that could reach five days. This electronic obstetrical calendar reconfirms Naegele's rule and at the same time adds a new rule in order to calculate the expected date of delivery when using the Hijrian date compared to the traditional pregnancy wheels. This electronic calendar is simple to use, more accurate and very helpful, particularly to physicians and patients who live in Arab countries where the Hijrian calendar is used as the official calendar.

Keywords: Hijrian calendar, Gregorian calendar, and Obstetrical calendar, Pregnancy wheels, Expected date of delivery.

Common wisdom says "whoever can not live with the electronic technology will not be able to live on this planet".
\end{abstract}

\section{Introduction}

The duration of term pregnancy is 280 days (40 weeks). Given the date of the last menstrual period (LMP) it is customary to calculate the expected date of delivery (EDD) by adding 7 days to the LMP and counting back 3 months (Naegele's Rule).

\footnotetext{
${ }^{*}$ Correspondence \& reprint request to: Dr. Faisal M. Tallab

P.O. Box 631, Jeddah 21421, Saudi Arabia

Accepted for publication: 28 September 2007. Received: 23 May 2007.
} 
In the current practice, pregnancy wheels (Fig. 1) provided by several pharmaceutical companies are used to calculate the EDD with an error of 5 days (Bracken and Belanger, 1989) ${ }^{[1]}$.

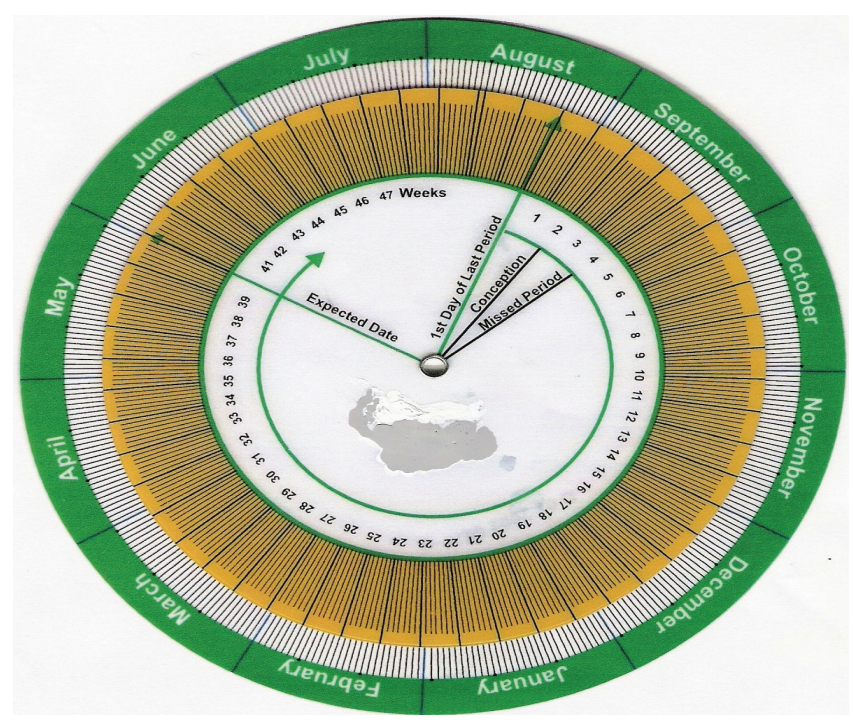

Fig. 1. Pregnancy wheel.

Internet research has shown that there are various programs of Gregorian electronic obstetric calendars. However, none have included the Hijrian calendar or the ability to convert from Hijrian to Gregorian the last menstrual period and the expected delivery date.

As the Hijrian date is widely used by Arab nations; therefore, this electronic program was designed.

\section{Method}

This electronic program is designed to work only on pocket personal computer and mobile phones with Microsoft windows using very complicated astronomical equations. It is composed of three pages (Fig. 2):

\section{Page 1 (used when the LMP is known)}

The user should enter the given LMP in Hijrian or Gregorian date and the computer will add 280 days (40 weeks) to it. It will then do 
automatic calculations and show the EDD immediately in both the Hijrian and Gregorian date.
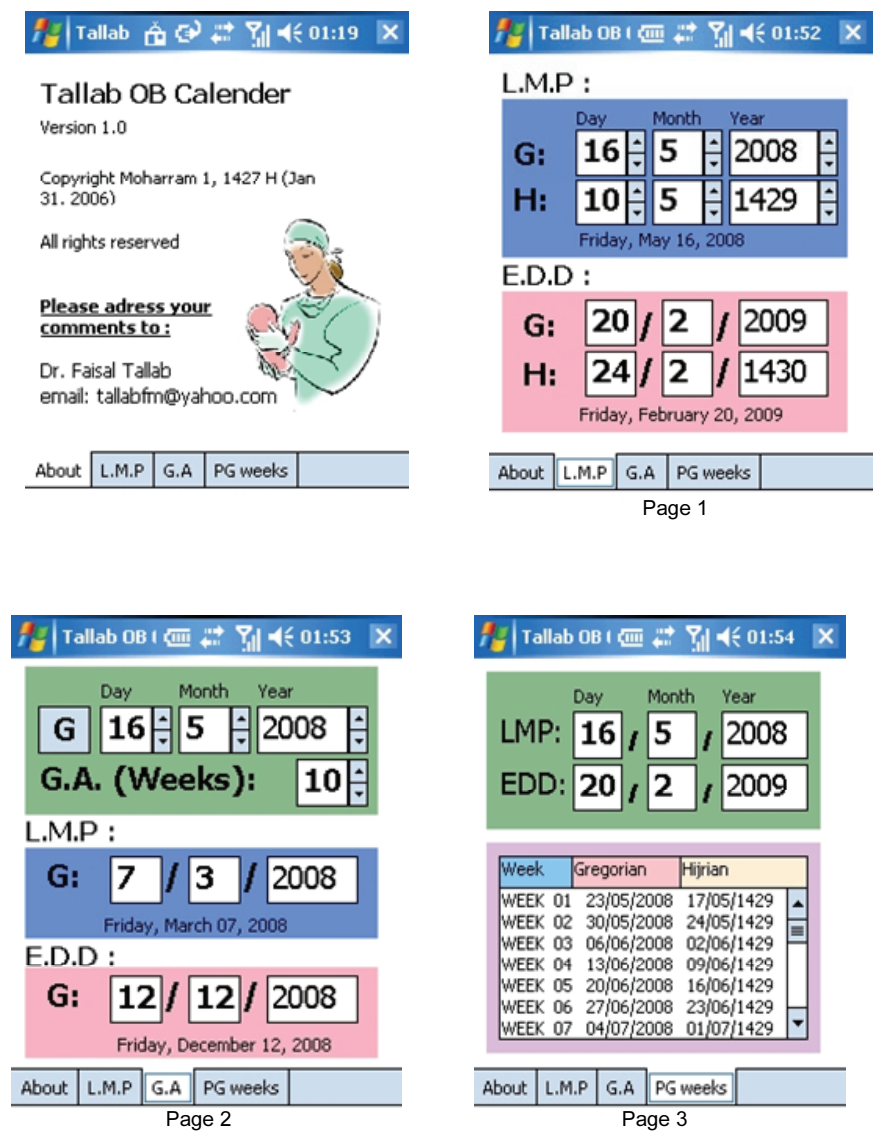

Fig. 2. Pictures of the electronic obstetrical calendar.

\section{Page 2 (used when the LMP is not known)}

The user should enter the gestational age at certain point in pregnancy at a given Hijrian or Gregorian date and the program will extrapolate the EDD in both dates and show it on the screen immediately.

\section{Page 3}

The user can use this page to have a look at the details of the 40week pregnancy period in both Hijrian and Gregorian dates. 


\section{Results}

This electronic obstetrical calendar was found to have the following advantages:

1. It has a high accuracy rate $=/ \pm$ one day error in calculation of the Gregorian date compared to the pregnancy wheel.

2. It has a high accuracy rate $= \pm \pm 1-2$ days error in calculation of the Hijrian date compared to the pregnancy wheel.

3. The difference in accuracy rates between both dates is because the Gregorian year is solar based ( \pm 365 days) while Hijrian year is lunar based ( \pm 355 days).

4. This program reconfirms Naegele's Rule for Gregorian calculation but at the same time provides a new rule for Hijrian calculation which is by adding 14 days to the LMP and counting back 3 months.

5. The built-in date converting facility will assist the user and there will be no longer need to carry a regular calendar or look for it in the clinics or in the wards.

6. The user, by downloading this program on pocket pc or mobile phone with Microsoft windows, will notice the difference in regards to convenience and simplicity of use compared to traditional pregnancy wheels.

\section{Conclusion}

This electronic obstetrical calendar is highly accurate and highly convenient with its built-in converting facility, and it is very simple to use. This will benefit a wide variety of people including obstetricians, general practitioners, midwives, medical students, and patients. In the very near future, this digital program will replace traditional pregnancy wheels should the pharmaceutical and computer companies adopt it.

\section{Dedication}

This paper is dedicated to the principle author's mother who died during childbirth many years ago.

\section{Reference}

[1] Bracken MB, Belanger K. Calculation of delivery dates. $N$ Engl J Med 1989; 321(21): 1483-1484. 
تقويم الحمل و الو لاده الإككترونى بالتاريخ الهجرى و الميلادى

$$
\text { فيصل محمود تلاب و أنس محمد مرزوقى أقنام الطب النسائي والتوليد، }
$$

مستشفى الملك عبدالعزيز ومركز الاورام وكلية الطب، جامعة الملك عبد العزيز لئيل

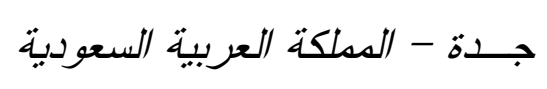

المستخلص. من المنعارف عليه أن حساب تاريخ الو لادة المتوقع يتم

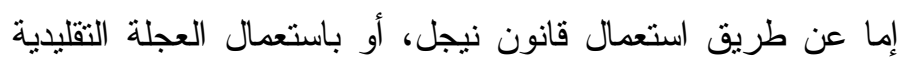

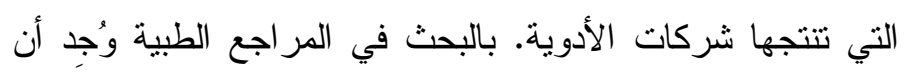

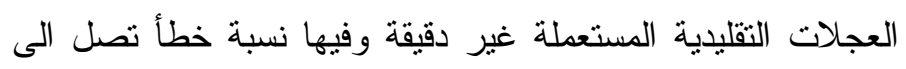

هذا البرنامج بناءً على معادلات فلكية يؤكد صحة قانون

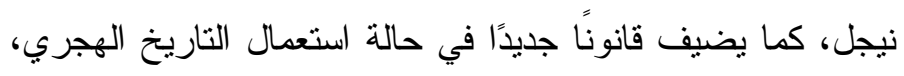

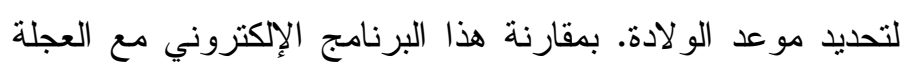

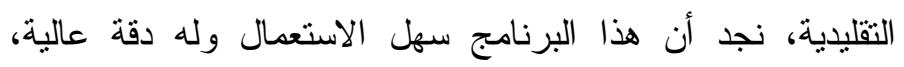
ويساعد العاملين في المجال الصحي، وخصوصنًا العاملين في الدول العربية التي تستخدم التاريخ الهجري بصفة رسمية. 